\title{
$O$ conceito de neurose em Gestalt terapia
}

\author{
Carlene Maria Dias Tenório
}

\begin{abstract}
RESUMO - De acordo com a abordagem gestáltica, a neurose é o resultado de processos inconscientes, repetitivos e obsoletos de interrupção do contato, gerando uma distorção na percepção da realidade, dificultando a recuperação do equilíbrio no campo organismo/meio e impedindo o crescimento do self. A neurose é, portanto, um enfraquecimento das funções de ego do self, resultando numa perda de fluidez entre contato e retraimento, estabelecendo-se uma fixação da fronteira em uma dessas polaridades. A necessidade organísmica primordial, e que está na base do desenvolvimento da neurose, é a fome. Neste sentido, a agressividade oral, através da mordida e da mastigação, é uma importante resistência contra as imposições do meio; é a capacidade para desestruturar o alimento, para que este possa ser devidamente assimilado pelo organismo. A assimilação através da mastigação está na base do desenvolvimento saudável, enquanto a introjeção está na base do desenvolvimento neurótico da personalidade.
\end{abstract}

Palavras-chave:Gestalt terapia, neurose, contato, introjeção.

\section{The concept of neurosis in Gestalt therapy}

\begin{abstract}
According to the Gestalt approach, neurosis is the result of unconscious, repetitive and obsolete processes of contact interruptions, producing a distorted perception of reality, making it harder to get back to the equilibrium in the field organism-environment, and preventing the self to grow. Therefore, neurosis is a weakness of self's ego functions, resulting in a loss of the free flow between contact and avoidance, establishing a boundary's fixation in one of these two polarities. The fundamental human need that is on the basis of the development of neurosis is hunger. In this way, oral aggression, characterized by acts of biting and chewing, is an important resistance against the environmental impositions. It's the capacity to digest the food in order to be well assimilated by the body. The assimilation through chewing is essential for a healthy development of the personality. On the other hand,introjection, swallowing without chewing, is related to the development of the neurotic personality.
\end{abstract}

Key words: Gestalt therapy, neurosis, contact, introjection.

Gestalt Terapeuta; Mestre e Doutoranda em Psicologia Clínica pela Universidade de Brasília-UNB; exprofessora da Universidade deFortaleza-UNIFOR; professora doCentro Universitáriode Brasília-UNICEUB; membro efetivo da diretoria e do corpo docente do Instituto de Gestalt Terapia de Brasília-IGTB E-mail: igtb.@ zas.com.br 


\section{A definição de Neurose}

Os teóricos da Gestalt Terapia desenvolveram uma compreensão dos processos patológicos do desenvolvimento a partir do estudo dos processos de auto-regulação organísmica e das formas saudáveis de funcionamento da fronteira de contato no campo organismo/meio.

Para podermos definir o conceito de neurose dentro dessa abordagem, precisamos partir da idéia de totalidade e de campo organismo/meio. O pressuposto de que organismo e meio constituem partes de um mesmo todo, onde um influencia o outro em constante relação de mutualidade, é um dos paradigmas centrais da Gestalt Terapia. A outra idéia importante é que o organismo é uma unidade integrada que se relaciona constantemente com seu meio e o órgão pelo qual se dá essa relação é definido como fronteira de contato. Tudo que se passa no organismo, no nível sensorial ou motor, se dá na fronteira de contato e é sempre uma função da interação organismo/meio. Neste sentido, o estudo da neurose ou da forma com o indivíduo atua em seu meio é o estudo dos processos da fronteira de contato. (Tenório, 1994)

A Gestalt Terapia acredita, portanto, que qualquer comportamento é sempre uma função do campo organismo/meio. Nesta perspectiva, vai ser uma relação de conflito existente entre o organismo e seu meio que inicialmente vai determinar a neurose, embora aconteça depois um processo de internalização desse conflito. Sobre isso, Perls (1975) esclarece:

"O conflito mais importante que pode gerar uma personalidade integrada ou neurótica é o conflito entre as necessidades sociais e biológicas do ser humano. (...) Entretanto, com muita freqüência, o autocontrole socialmente exigido pode ser conseguido às custas da desvirtualização ou deteriorização de grande parte das funções da personalidade humana, gerando as neuroses individuais e coletivas".(pp.78-79).

A neurose é, então, o resultado da tentativa desesperada do indivíduo para evitar o conflito e recuperar o equilíbrio na sua relação com o meio.

"Todos os distúrbios neuróticos surgem da incapacidade do indivíduo encontrar e manter o equilíbrio adequado entre ele e o resto do mundo e todos têm em comum o fato de que na neurose, o social e os limites do meio sejam sentidos como se estendendo demais sobre o indivíduo. O neurótico éo homem sobre quem a sociedade influi demasiadamente. Sua neurose é uma manobra defensiva para protegê-lo contra a ameaça de ser barrado por um mundo esmagador. Trata-se de sua técnica mais efetiva para manter o equilí- 
brio e o sentido de auto-regulação numa situação em que sente que as probabilidades estão todas contra ele"(Perls, 1981, p. 45).

Essa estratégia de sobrevivência e de auto-regulação, no entanto, tem como subproduto a alienação daquelas partes da personalidade que produzem o desequilíbrio do campo organismo/meio, resultando na criação de conflitos internos, que é a base do processo de formação das neuroses.

Em "Ego, fome e agressão", Perls considera o ser humano uma criatura essencialmente biológica com um impulso natural em direção ao equilíbrio e faz uma adaptação do conceito biológico de auto-regulação para explicar sua visão sobre o funcionamento psicológico.

Neste sentido, toda pessoa possui uma tendência inerente para organizar suas experiências em um todo significativo, através de processos constantes de formação e destruição de figuras, pelas quais se dá a auto-regulação do organismo ou seu ajustamento criativo no meio. Esse processo de auto-regulação, portanto, se dá em um ciclo espontâneo onde uma figura dominante emerge de um fundo indiferenciado, mobiliza energia, concentrando toda atenção sobre ela e após sua satisfação ou fechamento, através de uma ação e de um contato com o meio, ela desaparece gradualmente no fundo, de onde emerge uma nova figura. Este ciclo é o processo existencial subjacente a toda experiência humana e representa o paradigma pelo qual são descritos as formas de funcionamento saudável e neurótico do indivíduo (Clarkson, 1989).

Para a gestalt terapia, esse fluxo natural de auto-regulação ou esse processo de formação e destruição de figuras não interrompido é o estado saudável de todo organismo. A expressão natural da vitalidade e do funcionamento saudável é o impulso para atualização do self ou para a completa realização de suas necessidades, que requer, inevitavelmente, um contato satisfatório, sem interrupções, com o meio e consigo mesmo.

Perls, Hefferline e Goodman (1997) definem a neurose como o resultado de interrupções do ciclo de contato e da perda das funções de ego do self, uma vez que na interrupção do contato o que deveria ser rejeitado ou transformado é aceito passivamente, tendo como conseqüência a divisão do self. No entanto como a interrupção do contato e a aceitação passiva do que deveria ser rejeitado é uma forma de defesa do self, no sentido de tentar resolver um impasse existencial, no qual este se encontra diante de uma situação que é ao mesmo tempo intolerável e inevitável, preferimos dizer que a neurose é o resultado do enfraquecimento das funções de ego do self. Dizemos enfraquecimento porque devido à imaturidade do self da criança e à sua condição de impotência, fragilidade e dependência diante do adulto, suas funções de ego não são exercidas de forma adequada às 
suas próprias necessidades, mas sim às necessidades do outro que lhe são impostas. Em fim, diante de situações intoleráveis, as quais não podem ser evitadas nem transformadas, o self, através de suas funções de ego, prioriza a necessidade de sobrevivência em detrimento de seu prazer e de seu crescimento harmonioso, produzindo as neuroses.

\section{O Processo de formação das Neuroses}

Perls (1975), na tentativa de descrever o funcionamento saudável do indivíduo e de esboçar uma teoria que explicasse o nascimento da neurose, postulou estágios de desenvolvimento relacionados às etapas de nascimento dos dentes e classificou esses estágios em pré-natal, pré-dental (amamentação), incisivo (mordida) e molar (mastigação).

A criança ao nascer faz a transição do estágio pré-natal, caracterizado pela recepção passiva de oxigênio e de suprimento alimentar, para o estágio pré-dental, onde ela terá que fornecer a si mesma seu próprio oxigênio e seu alimento, através da respiração e da sucção. Com a erupção dos dentes incisivos e depois dos molares, a criança desenvolve a capacidade para atacar ou enfrentar os alimentos sólidos. Perls via a possibilidade de interrupção do desenvolvimento dessa capacidade como consequiência da punição pelo ato de morder o peito da mãe. Ele acreditava que a punição, ou a rápida e prematura retirada do peito, poderia resultar na inibição do ato de morder ou agredir, de importância fundamental no processo de autoregulação organísmica e atualização do self.

O emprego dos dentes é, portanto, a principal representação biológica de uma resistência oral saudável feita pelo contato ou pela agressão e não de uma resistência neurótica feita pela evitação do contato ou interrupção deste. Quem não emprega seus dentes estará perdendo a capacidade para empregar suas funções agressivas em seu próprio proveito.

O fato de não preparar o alimento para que este seja devidamente assimilado pelo organismo, terá repercussões drásticas na estrutura de personalidade do indivíduo. Nos piores casos de pouco desenvolvimento da capacidade de morder, mastigar e agredir, as pessoas continuam sendo crianças de peito a vida inteira e, permanecendo com essa atitude, podem se tornar eternas parasitas, esperando sempre algo em troca de nada, sem conseguir alcançar o equilíbrio necessário para uma vida adulta baseada no princípio de dar e receber. Desse modo, ao contrário da crença de Freud na primazia das resistências anais, ligadas à retenção ou recusa em deixar sair, Perls acreditava que existiam muitas outras formas de resistência e as mais importantes eram as resistências orais, relacionadas à recusa 
em deixar entrar, referentes às primeiras rejeições de alimento por parte da criança (Persl, 1975).

O ato de repugnar, por exemplo, é uma dessas resistências orais, é a rejeição emocional do alimento no momento em que este entra na boca e no estômago, ou quando este contato é apenas imaginado. Na ausência da resistência oral pela mordida ou mastigação, como consequiência de uma imaturidade ou inibição, a criança não encontra outra saída a não ser resistir pela repugnância, ou seja vomitando.

O repugnar significa, portanto, uma oposição ao alimento, uma interrupção do contato com algo que vem de fora, antes que este se converta em parte de nós mesmos, é uma alienação ou evitação daquilo que pode ser nocivo ao organismo e que não foi possível ser desestruturado pela agressão ou pelo contato.

Assim como a inibição do ato de morder pode gerar o ato de repugnar, a inibição da repugnância pode gerar o ato de introjetar ou engolir inteiro. Neste sentido, quando uma resistência natural é inibida pelo meio, o organismo, imediatamente, cria outro tipo de resistência, ou de defesa, como forma de sobreviver ou de manter seu equilíbrio diante de uma situação extremamente ameaçadora, que não pode ser enfrentada diretamente. Por exemplo, se a criança é castigada por ter recusado um alimento e é obrigada a comer aquilo de que não gosta, para resolver este conflito, ela o engole inteiro e rapidamente sem sentir seu péssimo sabor. A introjeção é, portanto, uma forma alternativa de resistência criada pelo organismo, depois de ter fracassado na luta contra a imposição pelo outro de algo nocivo e repugnante.

Embora seja uma forma de deixar entrar, a introjeção é um tipo de resistência neurótica, na medida em que interrompe o contato com o alimento, isto é, em vez de ser mastigado, ele simplesmente é engolido inteiro.

"Na introjeção, a pessoa neutraliza sua própria existência ao evitar a agressividade necessária para desestruturar aquilo que existe. É como se qualquer coisa que existisse fosse inviolável; ela não vai mudá-la, deve aceitála tal qual ela lhe chega" (Polster \& Polster, 1979, p.83).

Perls explica que a incorporação pelo organismo de coisas que vêm de fora, é feita em três fases distintas: introjeção total, introjeção parcial e assimilação, que correspondem às fases de sugar, morder e mastigar, referentes aos estágios pré-dental, incisivo e molar do desenvolvimento dos dentes. Tanto na introjeção total quanto na parcial, o material não é mastigado pelos molares trituradores, permanecendo como um corpo estranho em nosso organismo. Em contraste com a introjeção, vista como um processo patológico, Perls explica a assimilação como 
uma forma saudável de incorporação do mundo através do contato, onde o material vindo de fora é devidamente transformado pela mastigação ou agressividade natural do organismo, facilitando, assim, sua completa integração à estrutura do self.

"Quero dizer que o alimento psicológico que nos oferece o mundo externo - o alimento de fatos e atitudes sobre o qual se constróem as personalidades - tem que ser assimilado exatamente da mesma forma que nosso alimento real. Tem que ser desestruturado, analisado, separado e, de novo, reunido sob a forma que nos será mais valiosa. Se for meramente engolido inteiro não contribui para o desenvolvimento de nossas personalidades. Pelo contrário, nos torna algo semelhante a uma casa tão superlotada com coisas de outras pessoas que não sobra lugar para as coisas do dono"(Perls, 1981, p.47).

Polster \& Polster (1979) esclarecem, no entanto, que nem toda introjeção é patológica, nem sempre o material introjetado é tóxico e nem permanece inteiro dentro do organismo, às vezes ele pode ser nutritivo e assimilável. A criança, quando ainda não consegue mastigar, não pode transformar a substância para melhor lhe satisfazer, a única coisa que ela consegue é aceitar passivamente o alimento ou colocá-lo para fora, quando este lhe for repugnante e se não existirem fortes ameaças de punição ou de perder o amor dos pais, por ela ter desobedecido ou recusado o alimento. Quando o ambiente é de fato benéfico e merecedor de confiança, o material que ela recebe, na maioria das vezes, é nutritivo, assimilável e agradável. Uma vez que é permitido à criança recusar o alimento que não lhe agrada, os pais passam a reconhecer as verdadeiras preferências e necessidades de seus filhos, procurando sempre lhes oferecer aquilo que de fato pode the proporcionar satisfação, bem-estar e crescimento. No entanto, se o ambiente não for confiável e benéfico o material oferecido à criança pode ser tóxico e desagradável por ser incompatível com suas necessidades e caso seja introjetado, permanecerá como um corpo estranho e nocivo dentro do próprio organismo, impedindo seu processo natural de auto-regulação e crescimento.

Smith (1988) descreve, de forma clara e sucinta, o aspecto dinâmico e patológico da introjeção, seu papel na construção da neurose e na interrupção do processo de auto-regulação organísmica. Segundo Smith todo processo de interrupção do ciclo de contato está baseado na dinâmica do introjeto tóxico. Durante os primeiros anos de seu desenvolvimento, a criança manifesta espontaneamente suas necessidades e sentimentos e, muitas vezes, recebe de seus pais mensagens proibitivas que bloqueiam seu impulso natural para auto-regulação ou para busca da realização de suas necessidades.

Devido a profunda dependência da criança em relação a seus pais, as 
mensagens proibitivas são introjetadas, engolidas inteiras. Durante essa fase do processo de socialização, muitas das mensagens introjetadas são bio-negativas, isto é, são mensagens arbitrárias que não dão suporte à vitalidade da criança. As mensagens bio-negativas são, portanto, introjetos tóxicos. Estes introjetos usualmente são mantidos durante muito tempo de forma desconhecida e desintegrada do self. O resultado disso é a divisão interna da personalidade ou o conflito entre partes próprias do self e partes introjetadas, levando a um processo de alienação daquilo que verdadeiramente pertence à sua estrutura.

A mensagem proibitiva, como uma voz introjetada, faz com que a ameaça de perder o amor dos pais, por ter desobedecido a estes, se torne uma crença fóbica, condicionada a uma catástrofe iminente, sempre que as leis proibitivas não forem respeitadas. O introjeto tóxico carrega consigo um "deveria" ou "não deveria" associado a uma expectativa de catástrofe. Quanto maior for o número e a variedade de introjetos tóxicos, mais fóbica a pessoa se tornará e menos vitalidade ela terá, tornando-se cada vez mais neurótica.

A interrupção do contato, segundo Smith (1988), é, portanto, a essência da diminuição da vitalidade e a introjeção é o processo que permite a criação da neurose, é o processo pelo qual as mensagens tóxicas são incorporadas sem serem assimiladas ou integradas devidamente ao self.

Ao longo do processo de desenvolvimento, observa-se que a resistência, inicialmente feita pela criança contra coisas vindas de fora ou contra imposições externas, aos poucos vai se tornando uma resistência contra coisas vindas de dentro de si mesma, um sabotador internalizado que impede a realização das necessidades do próprio self, bloqueando seu processo de auto-regulação organísmica. É esse tipo de resistência, a interrupção, evitação do contato com aspectos próprios do self que gera a neurose.

Neste sentido, a neurose se caracteriza por uma estrutura de self fragilizada e dividida em duas partes que lutam constantemente uma contra a outra (dominador e dominado). A parte introjetada ou falsa (dominador - não devo sentir raiva), formada basicamente a partir do medo de ser punida ou abandonada, por garantir a sobrevivência da criança, torna-se a parte mais forte, enquanto a parte verdadeira ou não introjetada (dominada - sinto raiva)torna-se mais fraca, submetendo-se às imposições da parte introjetada, tornando-se alienada e projetada para fora das fronteiras do self. A alienação e a projeção, portanto, são formas de defesa ou de evitação e interrupção do contato com aquelas experiências que entram em conflito com os introjetos bionegativos, forçosamente reconhecidos pelo self como fazendo parte de sua própria estrutura.(Perls, 1981).

Na neurose o que é essencialmente próprio do self é alienado e colocado 
para fora das fronteiras (projeção), enquanto o que é essencialmente próprio do outro é identificado e colocado para dentro das fronteiras (introjeção). Desse modo, através de sucessivos processos de falsa alienação (projeção) e falsa identificação (introjeção) a função de ego do self perde a capacidade de fazer a adequada discriminação entre o que é próprio do self e do outro, entre o que é identificável e alienável, entre o que é tóxico e nutritivo no campo organismo/meio. Com essa incapacidade para fazer identificações e alienações de forma adequada, cria-se uma confusão de limite entre o self e o não self, entre o que vem de dentro e de fora. Por isso Perls, Hefferline e Goodman, 1997 dizem que a neurose é o resultado da perda das funções de ego do self. Como conseqüência da perda das funções de ego e da interrupção do contato na fronteira organismo/meio, acontece inevitavelmente uma percepção distorcida ou diminuída da realidade e de si mesmo.

A diminuição do contato com o meio e consigo mesmo, torna o neurótico confuso e inseguro sem poder mais identificar com clareza suas próprias necessidades. Deixa de ser criativo e espontâneo e está sempre controlando a si mesmo para não cometer erros ou desagradar o outro. Seu fluxo de conscientização ou de contato com sua experiência no aqui e agora está constantemente sendo bloqueado. Ele funciona basicamente pela interrupção de si mesmo, de sua respiração, de suas emoções e de sua atuação no mundo. Sua vida está repleta de dúvidas, medos e situações inacabadas que o fazem ficar preso ao passado e repetir compulsivamente os mesmos padrões de comportamento ou de ajustamento empregados anteriormente, na tentativa desesperada de fechar o que ficou em aberto.

Na interrupção do contato está a origem da situação inacabada. Quando o processo de formação de figura é interrompido, a figura não é completada, consequentemente ela não retorna inteiramente para o fundo ou não desaparece completamente do campo, permanecendo marcas, fantasmas, lembranças ou impressões da imagem de uma figura que ficou incompleta, de uma gestalt que ficou aberta ou de uma necessidade que ficou insatisfeita.

Após sucessivas interrupções do contato o campo perceptivo vai se tornando cada vez mais confuso, situações inacabadas do passado passam a interferir na percepção da situação atual e a pessoa passa a perceber o mundo com lentes embaçadas que distorcem a realidade.

Aos poucos ela vai perdendo a capacidade de separar e estabelecer limites ente ela e o outro, vai se misturando e se confundindo com o meio, vai perdendo o contato com a realidade. Cada vez mais as situações inacabadas insistem em voltar ao primeiro plano da consciência para serem concluídas, contaminado e perturbando o campo sem deixar que a próxima figura emerja de forma clara.

As próximas figuras serão inevitavelmente pouco definidas e intensamente 
permeadas de significados e aspectos referentes às figuras não completadas anteriormente.Esse fenômeno de contaminação e perturbação do campo pode ser compreendido em outros termos como sendo o resultado de mecanismos de projeção ou de transferência onde a pessoa traz para o presente os significados referentes às situações do passado e percebe o outro, a relação com este ou a realidade atual, de maneira deformada pelos conteúdos próprios de seu mundo interno e subjetivo.

É claro que esse fenômeno de perturbação do campo pela contaminação de figuras inacabadas é inevitável e de certa forma faz parte do processo natural de relação com o outro e com a realidade. No entanto, esse fenômeno gera neurose quando ele se torna predominante, impedindo o contato pleno com o outro e consigo mesmo, que interfere na recuperação do equilíbrio organismo/meio, no processo de integração e atualização do self.

A fuga, evitação ou interrupção do contato, como já podemos perceber, é uma das principais características da neurose. Enquanto a destruição pela agressão do que é nocivo à integridade do self, é característica do funcionamento saudável, pois envolve confronto e contato não interrompido.

É importante esclarecer, no entanto, que nem sempre a fuga e a evitação são patológicas. No princípio, esse mecanismo pode ter sido a única saída encontrada pelo self no sentido de preservar sua integridade e manter seu equilíbrio com o meio. Desse modo, todos os tipos de interrupção do contato são potencialmente saudáveis, desde que sejam adequados à realidade do momento, que representem uma forma criativa de adaptar-se ao meio, que não sejam uma mera repetição automática e inconsciente de padrões arcaicos de comportamentos aprendidos anteriormente, por terem sido eficientes em algumas situações, mas que agora se tornaram inadequados e obsoletos.

A evitação biológica de contatos perigosos, em geral, é importante para a auto-preservação e manutenção de conceitos com os quais nos identificamos, que estão dentro de nossas fronteiras e que são valiosos para nós. Qualquer coisa que ameace deteriorar o todo ou partes do self é percebida como perigosa ou hostil e tem que ser aniquilada seja por meio do contato (destruição) ou da interrupção deste (fuga). A desvantagem da fuga é quando ela se torna crônica, gerando a possibilidade de uma desintegração mais profunda do self. Todo contato, seja ele hostil ou amistoso, acrescenta novas experiências, que, ao serem integradas por assimilação, contribuem para o desenvolvimento de nossas potencialidades, desde que não esteja carregado de perigo insuportável, ameaçando nossa estrutura de self. Nestes casos, fugir ou evitar o contato pode ser uma resistência ou defesa natural do organismo contra a possibilidade de um sofrimento ou de um conflito intolerável (Perls, 1981). 


\section{As Fixações no Contato e no Retraimento}

Swanson (1988) partindo do ponto de vista de que a experiência humana se dá na fronteira de contato organismo/meio, através de um processo de formação e destruição de figuras, caracterizado por um ritmo apropriado de contato e retraimento, estabeleceu que de uma maneira geral, as pessoas neuróticas se diferenciam basicamente por duas formas de funcionamento: elas tendem a se fixar no contato, permanecendo em um estado de abertura indiscriminada para o mundo, ou tendem a se fixar no retraimento, permanecendo em um estado de fechamento, evitando, ao máximo, o contato com o meio.

O contato é basicamente movimento para fora, é aproximação, identificação e formação de figura, enquanto o retraimento é movimento de volta para o fundo, para dentro de si mesmo, é afastamento e alienação. Através desses dois movimentos opostos, contato e retraimento, o organismo discrimina o que é identificável e alienável no campo e se auto-regula. Na medida em que contato e retraimento se processam indevidamente, isto é, quando o self perde suas funções de ego, a fronteira de contato se torna rígida ou perturbada, ocorrendo uma fixação na permeabilidade, abertura ou contato, que permite a entrada indiscriminada de tudo que vem de fora, inclusive do que é tóxico, ou uma fixação na impermeabilidade, fechamento ou retraimento, que impede a entrada, inclusive do que é nutritivo, favorável ao equilíbrio e crescimento do self.

Examinando atentamente a descrição dos vários distúrbios da fronteira de contato, introjeção, projeção, retroflexão, proflexão, confluência e egotismo, descobrimos que é possível reunir suas características no sentido de fazer um delineamento dessas duas formas distintas de funcionamento da fronteira de contato. A introjeção, proflexão e confluência, por exemplo, estão claramente relacionadas com a fixação no contato, enquanto a projeção, retroflexão e egotismo relacionam-se com a fixação no retraimento. (Tenório, 1994).

Em linhas gerais, a pessoa que funciona basicamente pela fixação no contato abre inteiramente suas fronteiras para o outro no sentido de evitar o conflito e o abandono. Ela aceita tudo e não se opõe a quase nada que lhe é imposto. Engole inteiro tudo que parece ser incompatível com sua estrutura introjetada de self. Evita qualquer conflito através da submissão, concorda com tudo e faz tudo que é esperado pelos outros, abrindo mão de seus interesses e necessidades. Não consegue tomar suas próprias decisões e fazer suas escolhas com base em sua própria experiência. Precisa do outro para saber o que quer e para definir o que é melhor para si mesma. Deposita confiança total nas outras pessoas e nenhuma em si mesma. Tem medo de ficar só, por isso se entrega totalmente, supervaloriza o outro e se sente completamente dependente deste. Não tem capacidade para 
atuar de forma agressiva que é necessária em todo contato com o novo, uma vez que sua agressividade foi amplamente diminuída. Ela não sabe lutar, discordar ou pedir diretamente, apenas aceita ou manipula. Como não conseguiu desenvolver um suficiente auto-apoio, essa pessoa é extremamente voltada para os outros, pois acredita que só através destes é possível encontrar sua própria felicidade. Por esse motivo, ela se submete inteiramente aos outros ou os manipula, investindo toda sua energia para agradá-los e satisfazer suas expectativas, para que estes lhe proporcione aquilo que ela precisa, sem saber como conseguir o que deseja através de seus próprios meios, de forma direta e independente.(Tenório, 1994).

Por outro lado, a pessoa fixada no retraimento se fecha dentro de si mesma, criando uma barreira que bloqueia o contato com os outros. Ela faz isso porque projetou no meio tudo que fazia parte dela mesma, mas era considerado intolerável. Agora ela se defende do mundo, pois acredita que as outras pessoas têm tudo que ela acredita ser perigoso e ameaçador para si mesma. Toda energia e ação que deveriam ser orientadas para o meio são voltadas para dentro do próprio organismo, evitando, assim, o contato com o outro através da retroflexão. Ela se fecha para o outro, porque também tem medo de ser invadida ou de ser engolida por ele. Procura ser auto-suficiente, pois não confia em ninguém. Faz a si mesma aquilo que gostaria de fazer aos outros ou que os outros lhe fizessem. Culpa as pessoas por tudo e acha que pode se tornar vítima do mundo se não se cuidar e se proteger dos outros.

A relação dessa pessoa consigo mesma é de falsa admiração e enaltecimento e com os outros é de falsa rejeição e desvalorização, já que no fundo ela se sente inferior e incapaz. E como o outro é visto como perigoso ela tem que passar a imagem de que é superior e auto-suficiente. Ela está sempre muito preocupada consigo mesma, como se estivesse constantemente numa luta de vida ou morte com o mundo. Para suportar o isolamento, ela tenta se amar e se relacionar consigo mesma. Está sempre se auto-observando e em contato vivo com seus próprios pensamentos, sentimentos, gestos, etc. Planeja e mastiga excessivamente seus planos, sua atuação tem que ser quase perfeita, não pode errar um milímetro, não pode falhar, não pode perder uma batalha, pois se isto acontecer, o outro pode lhe dominar ou lhe destruir. Controla sua raiva e seu amor porque tem medo do que pode acontecer se deixar que estes sentimentos sejam liberados completamente. Não agride, porque tem medo de destruir ou de ser destruída, nem se aproxima muito, porque tem medo de ser sufocada ou de sufocar outro.(Tenório, 1994).

Finalmente é importante colocar que na neurose a pessoa é tomada por um estado crônico de insatisfação, insegurança, confusão e ansiedade, que lhe obriga a utilizar de forma compulsiva e inconsciente todos os mecanismos de interrupção 
do contato, na tentativa desesperada de aliviar seu sofrimento e manter sua estrutura fragilizada de self.

Desse modo, a neurose é mantida pela introjeção na medida em que a pessoa continua fazendo, de maneira cega e automática, falsas identificações com o que é próprio do outro com o objetivo de fortalecer sua estrutura introjetada de self e assim poder se defender melhor contra a constante ameaça de uma emergência em primeiro plano de experiências autênticas consideradas perigosas por serem incompatíveis com os introjetos bionegativos. (Tenório, 1994).

Através da deflexão o neurótico diminui a força do contato, evitando o confronto direto com aspectos da realidade interna ou externa que geram conflitos. (Tenório, 1994).

Na projeção o self coloca para fora de suas fronteiras e atribui ao outro tudo aquilo que pertence à sua própria estrutura mas é considerado insuportável, por ser gerador de conflito com o meio e consigo mesmo. (Tenório, 1994).

Pela retroflexão, a pessoa bloqueia a manifestação de uma necessidade autêntica, voltando para si mesma a energia e a ação que deveriam ser aplicadas no contato com o meio.

Através da confluência, o neurótico se mistura e se identifica com o outro, assumindo estrategicamente a identidade alheia para definir sua própria estrutura e evitar o conflito com o outro. (Tenório, 1994).

Na proflexão ele dá ao outro aquilo que gostaria de receber, com isto ele espera que esse outro lhe retribua fazendo o mesmo. Dessa forma o neurótico, inconscientemente, manipula o outro, fazendo com que este lhe dê "espontaneamente" aquilo que ele precisa, sem ter que pedir ou se humilhar. Este mecanismo é uma estratégia para não entrar em contato com a própria carência e para evitar a frustração de pedir e não ser atendido. (Tenório, 1994).

Pelo egotismo a pessoa se volta para si mesma num processo de autoobservação e preocupação, no sentido de fazer o melhor possível para satisfazer sua própria exigência narcísica de perfeição, utilizando o outro como meio e não como fim. No fundo o que ela quer é satisfazer a si mesma, em detrimento da satisfação do outro. Com isto ela se sente auto-suficiente, mascarando sua dependência em relação ao outro e sua dúvida com relação a seu próprio valor e competência. (Tenório, 1994).

Em todos esses mecanismos existem aspectos comuns que são próprios da neurose: baixa auto-estima e sentimento de menos valia; necessidade de aprovação e confirmação por parte do outro; internalização do outro como introjeto tóxico, ocupando um espaço demasiado dentro do self; divisão do self em dominador e dominado gerando conflito e ansiedade, sentimentos de culpa e submissão em 
relação ao dominador ou super-eu introjetado; confusão de limite entre o Eu e o Outro; fronteira de contato mal definida; dúvida com relação às suas prioridades; falta de auto-apoio e autoconfiança.

\section{Referências}

CLARKSON, P.(1989). Gestalt Conselling in Action. California:Sage Publications Ltda. PERLS,F.S.(1975).Yo, Hambre y Agressión: Los Comienzos de la Terapia gestaltica. México. D.F: Fondo de Cultura Econômica.

PERLS,F.S.(1981).Abordagem Gestáltica e Testemunha Ocular da Terapia. Rio de Janeiro: Zahar Editores.

PERLS,F.S; HEFFERLINE,R.F. \& GOODMAN, P.(1997).Gestalt Terapia.São Paulo: Summus.

POLSTER,E.\&POLSTER,M.(1979)GestaltTerapia Integrada. Belo Horizonte: Interlivros.

SMITH,E.W.L.(1988)Self-interruptions in the rhythm of contact and with drawal. The Gestalt Journal,11 (2), 37-57.

SWANSON, J.L.(1988).Boundary processes and boun dary states: a proposed revision of the Gestalt theory of boundary Disturbances. The Gestalt Journal, 11 (2), 5-24.

TENÓRIO,C.M.D.(1994)Os distúrbios da fronteira de contato: Um estudo teórico em Gestalt Terapia. Dissertação de Mestrado, Universidade de Brasília. Brasília. 